\title{
UJI KUALITAS UMUR SIMPAN MANISAN TAMARILLO
}

\author{
N.M.E.Yuliana ${ }^{1}$, L.Masdarini ${ }^{1}$, C.I.R.Marsiti ${ }^{2}$ \\ Program Studi Pendidikan Kesejahteraan Keluarga, Jurusan Teknologi \\ Industri,Fakultas Teknik dan Kejuruan \\ Universitas Pendidikan Ganesha \\ Singaraja, Indonesia \\ e-mail: evayuliana0107@gmail.com¹,masdarini@undiksha.ac.id ${ }^{1}$, \\ raka.marsiti@undiksha.ac.id ${ }^{2}$
}

\begin{abstract}
Abstrak
Manisan tamarillo merupakan salah satu produk awetan yang diolah dengan penambahan gula sebagai pemberi rasa manis. Penelitian ini bertujuan Untuk mengetahui kualitas umur simpan manisan tamarillo ditinjau dari rasa, tekstur, warna dan aroma. Objek dalam penelitian ini adalah uji kualitas umur simpan manisan tamarillo dinilai dari segi rasa, tekstur, warna dan aroma. Metode pengumpulan data yang digunakan dalam penelitian ini adalah metode observasi dengan instrument lembar uji kualitas umur simpan. Teknik analisis data yang digunakan yaitu deskriptif kuantitatif. Umur simpan tersebut dapat diketahui berdasarkan penurunan mutu kualitas manisan menggunakan metode ESS (Extended Storage Studies) dengan penyimpanan dalam kondisi normal sehari-hari. Hasil penelitian selama penyimpanan 56 hari menunjukkan dari aspek rasa memperoleh persentase $77,77 \%$ berada pada kategori baik, aspek tekstur dengan persentase $33,33 \%$ berada pada kategori kurang, aspek warna dengan persentase $55,55 \%$ berada pada kategori cukup, dan aspek aroma dengan persentase $55,55 \%$ berada pada kategori cukup. Umur simpan manisan tamarillo selama 56 hari dengan perubahan mutu yang signifikan yaitu kerusakan tekstur yang keras, warna manisan coklat dan diselimuti warna putih yang dominan dan aroma khas buah tamarillo berkurang dan tidak harum.
\end{abstract}

Kata kunci : Manisan Tamarillo, Kualitas Manisan, Umur Simpan

\begin{abstract}
Candied tamarillo is a durable product that is processed with the addition of sugar as a sweet taste This study aimed at determining the quality of tamarillo candied shelf life in terms of taste, texture, color and flavor. The object of this research was the quality test of the tamarillo candied shelf life was assessed in terms of taste, texture, color and flavor. Method of data collection used in this study was observation method with a shelf life quality test instrument. The data analysis technique used was quantitative descriptive. Shelf life can be determined regarding to the reduced-quality of the sweets quality using the ESS (Extended Storage Studies) method with storage of daily normal conditions. The results of the research during 56 days storage showed that the aspect of taste obtained $77.77 \%$ and it was in the good category, the texture aspect with a percentage of $33.33 \%$ was in the lack category, the color aspect with a percentage of $55.55 \%$ was in the sufficient category, and the flavor aspect with a percentage of $55.55 \%$ was in the sufficient category. Shelf life of tamarillo candied for 56 days had significant changes in quality, namely hard texture damage, color turned brown and covered with a dominant white color and the distinctive flavor of tamarillo fruit was reduced and not fragrant.
\end{abstract}

Keywords: Tamarillo Candied, Candied Quality, Shelf Life. 


\section{PENDAHULUAN}

Bali merupakan daerah yang memiliki hasil pertanian yang sangat melimpah, salah satunya penghasil di sektor buah yang cukup besar. Buah di Bali sangat banyak dimanfaatkan oleh masyarakat, selain untuk dikonsumsi langsung buah juga dipersembahkan sebagai sesajen untuk setiap upacara di Bali. Buah yang ada di Bali memiliki berbagai macam jenis tergantung dari daerah masing-masing seperti yang banyak ditanam dan tumbuh di dataran rendah seperti buah manggis, salak, mangga dan lainnya. Sedangkan di daerah dataran tinggi seperti daerah Kintamani hasil pertanian yang dihasilkan seperti jeruk, kopi, cabai, tomat dan terong belanda atau juga dikenal masyarakat dengan sebutan buah tamarillo.

Terong belanda atau tamarillo (Solanum betaceum) adalah jenis tanaman anggota keluarga terungterungan (Solanaceae) yang mulai di kembangkan di Bogor Jawa Barat sejak tahun 1941. Buah tamarillo berbentuk bulat telur, berukuran $3-10 \mathrm{~cm} \times 3-5 \mathrm{~cm}$, meruncing kedua ujungnya, bergelantungan, bertangkai panjang, daun keopaknya tidak rontok. Kulit buah tipis, licin berwarna kemarah-merahan, merah jingga sampai kekuning-kuningan, daging buahnya mengandung banyak sari buah, agak asam, berwarna kehitam-hitaman sampai kekuning-kuningan. Bijinya bulat pipih, tipis, dan keras (Wikipedia 2018).

Buah tamarillo dapat disimpan dalam keadaan normal, daya tahannya sekitar 1 minggu. Tetapi pada suhu penyimpanan dingin dengan suhu $3,5{ }^{\circ} \mathrm{C}$ sampai $1{ }^{\circ} \mathrm{C}$ dapat disimpan selama 4 minggu atau lebih. Karena umur simpan buah tamarillo segar hanya bisa bertahan selama seminggu, maka buah tamarillo dapat diolah menjadi produk yang bisa bertahan lama salah satunya yaitu produk manisan.

Manisan merupakan produk makanan yang dibuat dengan metode penggulaan, manisan merupakan salah satu olahan pangan yang banyak disukai oleh masyarakat, dimana manisan mengandung kadar gula yang tinggi. Pembuatan manisan juga merupakan salah satu alternatif memperpanjang umur simpan produk (Fachruddin,1998). Manisan dapat dibedakan menjadi dua yaitu manisan basah dan manisan kering. Hal yang mendasar yang membedakan manisan basah dan manisan kering adalah dari cara pembuatannya, umur simpan dan penampakannya (Fatah dan Yusuf Bacthtiar, 2004).

Penelitian pemanfaatan buah tamarillo pernah dilakukan dengan memanfaatkan buah tamarillo menjadi manisan yang dilakukan oleh Ni Luh Putu Dewi Hermawati, Universitas Pendidikan Ganesha: 2009, dengan judul "studi eksperimen pembuatan manisan tamarillo". Peneliti tertarik untuk melakukan perbaharuan pada penelitian yang dibuat sebelumnya mengenai kualitas manisan tamarillo. Penelitian yang sudah dilakukan belum melakukan uji kualitas pada aroma dari manisan tamarillo itu sendiri dan juga belum melakukan penelitian tentang umur simpan dari produk manisan tersebut sehingga produk yang dibuat tidak diketahui batas layaknya untuk dikonsumsi.

Manisan tamarillo merupakan produk awetan yang dapat bertahan lama, meskipun manisan tamarillo merupakan produk awetan, produk tersebut tentu saja memiliki umur simpan atau masa layak tidaknya dikonsumsi, selain itu juga agar masyarakat dapat mengetahui seberapa umur simpan manisan tanpa harus mengira-ngira sampai kapan produk tersebut masih bisa disimpan. Semakin lama produk tersebut disimpan maka produk manisan akan mengalami kerusakan yang dapat menurunkan kualitas dari manisan tersebut baik dari segi rasa, tekstur, warna dan aroma dari manisan itu sendiri. Jika tidak mencantumkan umur simpan produk tersebut bisa saja dikonsumsi dalam keadaan yang tidak layak sehingga dapat menimbulkan hal yang tidak diinginkan seperti keracunan makanan bahkan 
kematian. Selain itu kualitas suatu produk juga sangat ditentukan oleh aroma pada makanan jika makanan memiliki aroma yang tidak sedap tentu saja akan mempengaruhi produksi dan penjualan produk tersebut sehingga membuat masyarakat ragu untuk membeli produk manisan tamarillo.

Umur simpan memiliki hubungan yang erat terhadap produk karena umur simpan akan menggambarkan seberapa lama produk dapat bertahan pada kualitas yang sama, selama proses penyimpanan produk harus tetap menjaga penampilan, aroma, rasa, warna dan tekstur. Umur simpan manisan tamarillo dapat dipengaruhi oleh beberapa faktor antara lain bahan, sanitasi peralatan, proses pengolaha, cara pengemasan, cahaya dan mikrorganisme yang nantinya faktor tersebut dapat mengakibatkan terjadinya penurunan mutu lebih lanjut seperti kerusakan vitamin, perubahan bau, reaksi pencoklata, perubahan unsur organoleptic dan kemungkinan terrbentuknya racun.

Umur simpan atau shelf life didefinisikan sebagai rentang waktu yang dimiliki suatu produk mulai dari produksi hingga konsumsi, sebelum produk mengalami penurunan kualitas/rusak dan tidak layak untuk dikonsumsi dan hal ini berhubungan dengan kualitas pangan. Penurunan kualitas/kerusakan produk dapat dilihat dari parameter sensori. Umumnya penulisan umur simpan pada label kemasan menggunakan bahasa best before (baik digunakan sebelum) (Nurul Asiah,dkk,2018;)

Mengukur umur simpan dari manisan tamarillo nantinya akan mempengaruhi kualitas dan mutu dari manisan tamarillo tersebut baik dari segi rasa, tekstur, warna dan aroma. Dalam mengukur umur simpan, manisan tamarillo akan disimpan dengan menyimpan produk manisan pada kondisi normal sehari-hari sambil dilakukan pengamatan terhadap penurunan mutunya, hingga mencapai tingkat mutu kadarluwarsa yang akan di ujikan setiap 7 hari sekali.

Berdasarkan uraian diatas maka tujuan yang ingin dicapai dalam penelitian ini adalah Untuk mengetahui kualitas umur simpan manisan tamarillo ditinjau dari rasa, tekstur, warna dan aroma. Oleh karena itu dengan menguji umur simpan manisan diharapkan mampu mengetahui mutu manisan selama penyimpanan dan sejauh mana manisan dapat dikonsumsi dengan aman oleh masyarakat.

\section{METODE PENELITIAN}

Penelitian ini dilaksanakan selama 2 bulan mulai tanggal 2 Mei 2019 sampai dengan 27 Juni 2019. Tempat penelitian di Laboratorium Jurusan Teknologi Industi,, Program Studi Pendidikan Kesejahteraan Keluarga.

Pada penelitian ini penulis menggunakan studi eksperimen uji kualitas umur simpan manisan tamarillo jenis penelitian yang digunakan yaitu penelitian eksperimen. Dengan metode Extended Storage studies (ESS). ESS sering juga disebut metode konvensional, adalah penentuan tanggal kadaluwarsa dengan jalan menyimpan suatu seri produk pada kondisi normal sehari-hari sambil dilakukan pengamatan terhadap penurunan mutunya (usable quality) hingga mencapai tingkat mutu tidak layak konsumsi.

Dalam penelitian ini manisan tamarillo akan diujikan umur simpan manisan dengan tahapan yaitu tahap persiapan, tahap pengolahan, tahap penyimpaan dan tahap pengujian. Pada tahap persiapan buah tamarillo yang masih segar dan berwana merah dipilih untuk dijadikan manisan. Tahap pengolahan, yaitu mengolah manisan tamarillo menjadi manisan. Tolak ukur rasa diharapkan yaitu manis dan asam, warna merah kecoklatan, tekstur lunak dan kenyal dan aroma khas buah tamarillo dan harum aroma gula.

Terakhir adalah tahap pengujian yaitu melakukan uji kualitas umur simpan terhadap manisan tamarillo dilihat dari segi rasa, tekstur, warna dan aroma dengan 3 orang panelis menggunakan bantuan lembar kuesioner. Dari hasil uji tersebut diperoleh data yang kemudian dianalisi hingga mendapatkan kesimpulan. adalah :

Bahan manisan yang digunakan

1. $1 \mathrm{~kg}$ buah tamarillo merah matang

2. 350 gr gula pasir 
3. 10 gr garam

4. $500 \mathrm{ml}$ air

5. $500 \mathrm{ml}$ sari biji buah tamarillo

Cara membuat manisan tamarillo :

1. Buah tamarillo dipilih dengan cara memilih bahan yang baik atau tidak rusak dengan pastikan buah yang dipilih sudah matang.

2. Buah tamarillo yang sudah disortir dicuci hingga bersih dan terhindar dari kotoran.

3. Proses pemotongan dilakukan membentuk manisan menjadi 2 bagian agar lebih mudah diolah dan membuat manisan lebih menarik dilihat.

4. Buah tamarillo yang sudah dipotong kemudian dibuang bijinya dan yang dibuat manisan hanya daging buahnya saja.

5. Tahap perendamana ini manisan tamarillo direndam dalam larutan gula dan sari buah tamarillo untuk memberikan rasa tamarillo agar lebih terasa.

6. Proses perebusan merupakan proses dalam pembuatan manisan. Perebusan yang dilakukan dengan penambahan gula pasir sebagai penambah rasa pada manisan.dan terakhir dijemur hingga kering dibawah terik sinar matahari.

Alat yang digunakan antara lain : Timbangan, talenan, pisau, wajan, panci, gelas ukur, sendok kayu, sendok, sringan dan Loyang plastic parsel, tali kawat berwarna, toples.

Metode yang digunakan dalam penelitian ini adalah metode observasi dan alat pengumpulan data yang digunakan berupa lembar uji kualitas umur simpan. Metode observasi digunakan

\section{HASIL DAN PEMBAHASAN Hasil}

Pada penentuan umur simpan manisan tamarillo untuk menentukan mutu akhir manisan dilakukan penyimpanan selama 2 bulan yang dilakukan pada suhu normal sehari-hari dan diamati secara berkala setiap 7 hari sekali oleh 3 orang panelis sampai salah satu mutu manisan untuk mencari data mengenai buah tamarillo yang ada di Kabupaten Bangli dan lembar uji kualitas umur simpan digunkan untuk memberikan penilaian terhadap manisan. Hasil penilaian dari panelis, disusun dalam tabulasi nilai yang dikelmokkan berdasarkan hari dan kualitas mutu manisa seperti rasa, tekstur, warna dan aroma.

Setelah didapatkan tabulasi nilai dari masing-masing manisan dilakukan penghitungan persentase uji kualitas pada masing-masing tingkat kualitas yang digunakan perbandingan antara jumlah panelis yang memilih tingkat kualitas 1,2 dan 3 dengan jumlah seluruh panelis yang ada kemudian dikalikan seratus persen. yaitu :

Adapun rumus yang digunakan

$$
\mathrm{N}=\frac{\sum \mathrm{X}}{S M I} \times 100 \%
$$

Keterangan :

$\mathrm{N}=$ Persentase uji kualitas (rasa, tekstur, warna dan aroma)

$\Sigma X=$ Jumlah penilaian panelis terhadap kualitas manisan tamarillo masing-masing skor (rasa, tekstur, warna dan aroma)

SMI = skor maksimal ideal

Acuan persentase pengambilan keputusan yang digunakan untuk menetukan kualitas umur simpan manisan tamarillo dilihat dari segi rasa, tekstur, warna dan aroma adalah sebagai berikut :

$$
\begin{aligned}
& 81 \%-100 \% \text { = sangat baik } \\
& 61 \%-80 \%=\text { baik } \\
& 41 \%-60 \%=\text { cukup } \\
& 21 \%-40 \%=\text { kurang } \\
& 1 \%-20 \% \text { = sangat kurang }
\end{aligned}
$$

mengalami penurunan tercepat baik dari segi rasa, tekstur warna dan aroma sampai tidak bisa diterima lagi. Parameter pengujian meliputi karakteristik rasa, tekstur, warna dan aroma sampai karakteristik mutu mengalami kerusakan yang signifikan. 
Tabel 1. Hasil persentase uji kualitas umur simpan manisan tamarillo penyimpanan selama 2 bulan. (\%)

\begin{tabular}{|c|c|c|c|c|}
\hline $\begin{array}{c}\text { Hari }- \\
\text { ke }\end{array}$ & Rasa & Tekstur & Warna & Aroma \\
\hline 0 & $100 \%$ & $100 \%$ & $100 \%$ & $100 \%$ \\
\hline 7 & $100 \%$ & $100 \%$ & $100 \%$ & $100 \%$ \\
\hline 14 & $100 \%$ & $100 \%$ & $100 \%$ & $100 \%$ \\
\hline 21 & $100 \%$ & $77,77 \%$ & $100 \%$ & $88,88 \%$ \\
\hline 28 & $100 \%$ & $77,77 \%$ & $100 \%$ & $88,88 \%$ \\
\hline 35 & $100 \%$ & $66,66 \%$ & $100 \%$ & $88,88 \%$ \\
\hline 42 & $100 \%$ & $66,66 \%$ & $100 \%$ & $88,88 \%$ \\
\hline 49 & $88,88 \%$ & $44,44 \%$ & $77,77 \%$ & $77,77 \%$ \\
\hline 56 & $77,77 \%$ & $33,33 \%$ & $55,55 \%$ & $55,55 \%$ \\
\hline
\end{tabular}

Berdasarkan tabel 1 di atas manisan tamarillo pada hari ke nol (0) berada pada kategori sangat baik dengan pesentase rasa $100 \%$ sesuai tolak ukur memiliki rasa asam dan manis, tekstur sangat baik dengan persentase $100 \%$ sesuai dengan tolak ukur yaitu memilki tekstur yang lunak dan kenyal, dalam mutu warna berada pada kategori sangat baik dengan persentase $100 \%$ sesuai dengan tolak ukur yaitu merah kecoklatan dan aroma berada pada kategori sangat baik dengan persentase $100 \%$ sesuai dengan tolak ukur yaitu aroma tamarillo yang khas dan harum.

Berikut adalah grafik perubahan mutu manisan tamarillo:

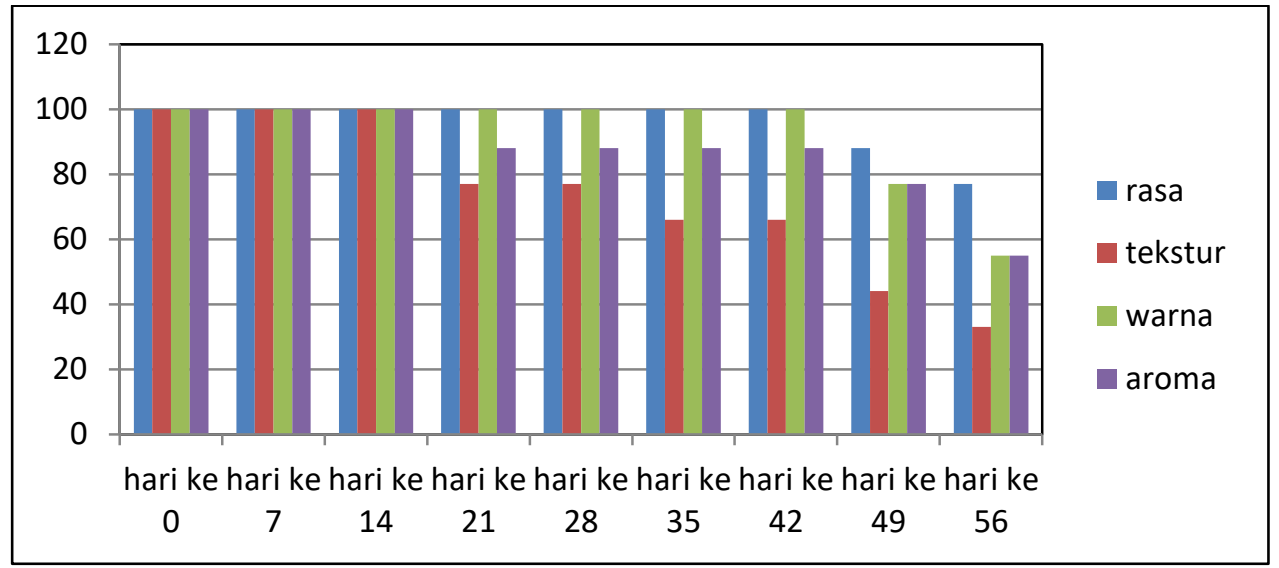

Gambar 1. Diagram Uji Kualitas umur simpan manisan tamarillo

Berdasarkan gambar 1 di atas pada hari ke 21 manisan tamarillo mengalami penurun mutu pada tekstur yang turun ke persentase $77,77 \%$ yaitu dalam kategori baik dengan tolak ukur yaitu kenyal sedikit keras. Dan pada kategori aroma juga mengalami penurunan mutu dengan persentase 66,66 \% dalam kategori baik sesuai tolak ukur yaitu beraroma khas buah tamarillo dan sedikit harum. Dan pada hari ke 35 terjadi penurunan mutu pada tekstur dengan persentase $66,66 \%$ dan masih dalam kategori baik dan sesuai dengan tolak ukur yaitu kenyal sedikit keras. Umur simpan manisan pada hari ke 56 dengan hasil rasa dengan persentase $77,77 \%$, tekstur dengan persentase $33,33 \%$, warna dengan

persentase $55,55 \%$ dan aroma dengan persentase $55,55 \%$. Setelah penyimpanan selama 2 bulan selesai dan sudah mendapatkan hasil kemudian dipilih salah satu yang memiliki umur simpan paling pendek dan memberi pengaruh yang signifikan yaitu pada mutu tekstur manisan yang sudah rusak pada hari ke 56 dengan 
tekstur yang keras dengan persentase $33,33 \%$ dalam kategori kurang dan pada mutu warna manisan sudah diselimuti warna putih yang dominan dimana hal tersebut menandakan manisan sudah rusak dengan didukung oleh jurnal Desy

\begin{tabular}{|c|c|c|}
\hline No & Gambar & Keterangan \\
\hline 1 & & $\begin{array}{l}\text { Kondisi manisan pada hari ke } 0 \\
\text { Rasa Manis asam, tekstur lunak } \\
\text { kenyal, warna merah kecoklatan, dan } \\
\text { aroma khas buah tamarillo dan harum }\end{array}$ \\
\hline 2 & & $\begin{array}{l}\text { Kondisi manisan pada hari ke } 7 \\
\text { Rasa Manis asam, tekstur lunak } \\
\text { kenyal, warna merah kecoklatan, dan } \\
\text { aroma khas buah tamarillo dan harum }\end{array}$ \\
\hline 3 & & $\begin{array}{l}\text { Kondisi manisan pada hari ke } 14 \\
\text { Rasa Manis asam, tekstur lunak } \\
\text { kenyal, warna merah kecoklatan, dan } \\
\text { aroma khas buah tamarillo dan harum }\end{array}$ \\
\hline 4 & & $\begin{array}{l}\text { Kondisi manisan pada hari ke } 21 \\
\text { Rasa Manis asam, tekstur menurun } \\
\text { kenyal sedikit keras, warna merah } \\
\text { kecoklatan, dan aroma khas buah } \\
\text { tamarillo dan harum }\end{array}$ \\
\hline 5 & & $\begin{array}{l}\text { Kondisi manisan pada hari ke } 28 \\
\text { Rasa Manis asam, tekstur menurun } \\
\text { kenyal sedikit keras, warna merah } \\
\text { kecoklatan, dan aroma sedikit } \\
\text { menurun dengan aroma khas buah } \\
\text { tamarillo dan harum }\end{array}$ \\
\hline 6 & & $\begin{array}{l}\text { Kondisi manisan pada hari ke } 35 \\
\text { Rrasa Manis asam, tekstur menurun } \\
\text { kenyal sedikit keras, warna merah } \\
\text { kecoklatan, dan aroma sedikit } \\
\text { menurun dengan aroma khas buah } \\
\text { tamarillo dan harum }\end{array}$ \\
\hline
\end{tabular}

Nofriati, 2013 Sehingga penilaian dihentikan agar tidak terjadi hal yang tidak diinginkan kepada panelis.

Berikut ini kondisi manisan selama penyimpanan dapat dilihat pada gambar : 


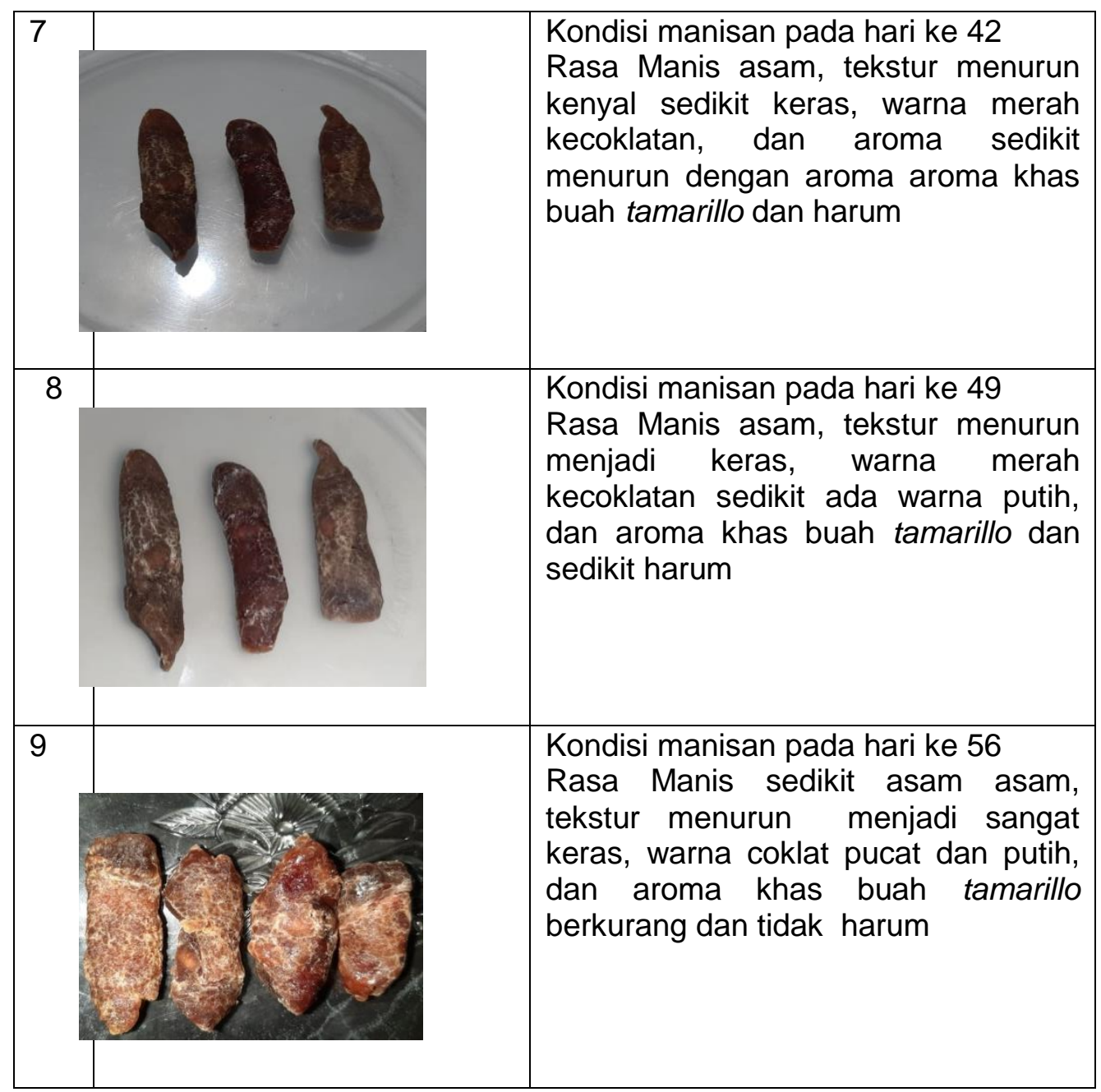

Gambar 2. Kondisi manisan tamarillo

Sumber : dokumentasi peneliti

\section{PEMBAHASAN}

Pada tahap uji kualitas umur simpan manisan tamarillo disimpan selama 2 bulan untuk mengetahui perubahan dan kerusakan yang terjadi pada manisan sehingga dapat mengetahui seberapa lama manisan dapat disimpan secara aman dan masih dalam keadaan yang baik. Proes uji umur simpan diawali dengan proses pembutan manisan tamarillo kemudian dilanjutkan dengan proses penyimpanan dilakukan dengan cara menyimpan 1 seri produk manisan disuhu ruangan atau suhu normal sehari-hari, kemudian akan dilihat perubahan yang akan terjadi selama penyimpanan. Pemantauan manisan dilakukan setiap 7 hari sekali selama 2 bulan. Penyimpanan akan dihentikan ketika salah satu kualitas manisan mengalami perubahan paling cepat baik dari rasa, tekstur, warna dan aroma. Hal tersebut dilakukan agar tidak terjadi satu hal yang tidak diingikan kepada panelis seperti keracunan. Selama pengamatan akan dilihat perubahan mutu yang terjadi adalah sebagai berikut :

(1) Kualitas umur simpan manisan tamarillo dari aspek rasa

Rasa merupakan salah satu penilaian penting untuk produk pangan. Pada awal penyimpanan, skor penilaian terhadap rasa manisan yang disimpan pada suhu normal sehari-hari dengan skor tertinggi yaitu 3 dengan hasil persentase $100 \%$ dalam ketgori sangat baik dengan rasa manis dan asam. Rasa asam didapatkan dari buah tamarillo itu sendiri dimana buah tamarillo merah memiliki 
rasa asam yang sangat tajam dan rasa manis didapatkan dari penamabahan gula pada proses pembuatan manisan sehingga rasa manisan menjadi manis dan asam.

Penurunan tingkat kesukaan terhadap rasa dimulai pada hari ke 49 dengan persentase $88,88 \%$ dengan penurunan sekitar $20 \%$ dari mutu awal dan masih dalam kategori sangat baik dan penurun pada hari ke 56 menjadi 77,77\% dengan ketegori baik dengan rasa manis dan sedikit asam. Penurunan mutu yang terjadi sekitar $30 \%$ dari hari ke 0 hingga hari ke 56. Penurunan rasa manis pada manisan disebabkan dengan tejadinya penurunan total gula yang diduga berhubungan dengan jumlah mikroba. Untuk mempertahankan hidupnya mikroba perlu makanan atau energi yang sebagian besar berasal dari gula yang terdapat dari manisan. Hal inilah yang menyebabkan total gula menurun pada manisan.

(2) Kualitas umur simpan manisan tamarillo dari aspek tekstur

Penilaian tekstur manisan tamarillo oleh panelis meliputi tektur lunak pada manisan. Selama penyimpanan tekstur manisan akan mengalami perubahan. Oleh karena itu, perlu diketahui sejauh mana konsumen yang diwakilkan oleh 3 panelis dapat menerima perubahan tekstur pada manisan. Pada hari ke 0 sampai hari ke 14 tekstur manisan dalam kategori sangat baik dengan persentase $100 \%$ dengan tekstur yang lunak kenyal. Tekstur lunak dan kenyal diperoleh karena tekstur buah tamarillo yang lunak ketika diolah menjadi manisan akan semakin lunak dan kenyal karenan buah yang memiliki tekstur lunak ketika direbus dan diolah menjadi manisan akan semakin lunak dan kenyal sama seperti tekstur buah tomat yang menghasilkan manisan tomat yang baik memiliki tekstur lunak dan kenyal (Finarsih Tendean,2016). Penurunan mutu tekstur manisan sudah mulai terjadi pada hari ke 21 dengan persentase $77,77 \%$ dalam kategori baik perubahan tekstur menjadi kenyal dan sedikit keras dengan penurunan sekitaran $30 \%$. Penurunan terjadi kembali pada hari ke 35 dengan persentase $66,66 \%$ dengan tekstur kenyal dan sedikit keras dan masih dalam kategori baik, penurunan pada hari ke 49 dengan persentase penurunan sekitaran $50 \%$ yaitu pada kategori cukup dengan persentase $55,55 \%$ dengan tekstur keras. Dan penurunan mutu manisan pada hari ke 56 yaitu dengan persentase 33,33\% dalam kategori kurang dengan perubahan tekstur yang sangat keras. Tekstur keras manisan menandakan manisan sudah rusak karena susah dikunyah hal ini disebabkan oleh terjadinya pengkristalan gula yang menyebakan manisan mengalami kekerasan dan berkurangnya kadar air yang terdapat pada manisan, sehingga manisan tamarillo mengalami kerusakan pada hari ke 56 dan tidak dapat dikonsumsi lagi karena sudah dalam kondisi rusak dan tidak layak dikonsumsi hal ini didukung oleh "Desy Nofriati, 2013". Pengerasan pada manisan tidak dapat dihindari karena proses penambahan pada manisan yang menyebabkan manisn akan menjadi keras karena pengkristalan gula. Apabila gula pada manisan dikurangi akan berpengaruh terhadap rasa pada manisan.

(3) Kualitas umur simpan manisan tamarillo dari aspek warna

Warna dari suatu makanan merupakan salah satu komponen yang mempengaruhi penampilan makanan yang dihidangkan untuk daya tarik minat konsumen. Warna yang kurang menarik akan menyebabkan produk tersebut kurang diminati. Warna pada awal penyimpanan manisan tamarillo dalam kategori sangat baik dengan warna merah kecoklatan dengan persentase 100\%. Penurunan awal pada kualitas warna manisan terjadi pada hari ke 49 dengan persentase $77,77 \%$ dengan kategori baik dengan warna merahan kecoklatan sedikit putih.warna mengalami peruabahan dengan sedkit warna putih pada manisan disebabkan manisan sudah muali mengalami pengkristalan tetapi tidak terlalu dominan. Pada hari ke 56 pada kategori cukup dengan persentase $55,55 \%$ dengan warna coklat pucat dan dominan putih. Warna putih yang dominan ini dikarenakan pengkriatalan gula pada manisan semakin bertambah dan semakin 
terlihat jelas kerena penyimpanan semakin lama warna manisan menjadi coklat dan dominan diselimuti pengkristalan gula yang berwana putih. Manisan tamarillo dinyatakan sudah rusak pada hari ke 56 karena manisan sudah diselimuti warna putih gula yang berarti sudah tidak baik dan banyaknya tumbuh mikroorganisme. Perubahan warna merah hingga menjadi coklat dan dominan putih tesebut disebabkan oleh terjadinya pengkristalan gula dan diikuti kontaminasi mikroorganisme, beberapa sifat dari gula antara lain apabila air diuapkan dari larutan gula maka gula akan mengkristal (Potter dan Hotchkist, 1995).

(4) Kualitas umur simpan manisan tamarillo dari aspek aroma

Aroma sangat berpengaruh terhadap produk makanan. Aroma manisan tamarillo pada hari ke 0 dalam kategori sangat baik dengan dengan persentase $100 \%$ aroma khas buah tamarillo dan harum. Aroma harum yang dimaksud adalah adanya aroma gula yang

\section{SIMPULAN DAN SARAN}

Berdasarkan uraian hasil dan pembahasan maka dapat ditarik kesimpulan yaitu Penurunan kualitas mutu manisan dimulai pada hari ke 21 dengan awal penurunan dari segi tekstur dan aroma. Dan umur simpan manisan tamarillo berakhir selama 56 hari dengan perubahan yang signifikan pada tekstur, warna dan aroma manisan. Dengan hasil segi rasa $77,77 \%$ dalam kategori baik dengan rasa manis dan sedikit asam, tekstur 33,33 \% dalam kategori kurang dengan kategori sangat keras, warna $55,55 \%$ kategori cukup pada kategori coklat pucat dan dominan putih, aroma $55,55 \%$ dengan kategori cukup dengan aroma khas tamarillo berkurang dan tidak harum .

\section{Saran}

Untuk memperoleh hasil manisan yang maksimal hal yang perlu di perhatikan adalah proses pengeringan agar tidak dikeringkan lebih dari 3 hari ketika cuaca panas.

Untuk manisan yang setengah kering sebaiknya dihilangkan terlebih ada pada manisan tamarillo. Penurunan awal terjadi pada hari ke 21 dengan kategori masih sangat baik dengan persentase $88,88 \%$.Penurunan selanjutnya mulai terjadi pada hari ke 49 dengan persentase $77,77 \%$ dalam kategori baik dengan aroma khas buah tamarillo masih bertahan hanya aroma harum gula mulai berkurang hal tersebut dikarenakan oleh faktor suhu yang menyebakan aroma gula sedikit berkurang, penurunan selanjutnya pada hari ke 56 mengalami penurunan sebesar $50 \%$ dalam kategori cukup dengan persentase $55,55 \%$ aroma yang sudah mulai berkurang yaitu aroma buah tamarillo berkurang dan aroma harum juga mulai tidak tercium lagi. Manisan yang dalam kategori layak adalah memiliki aroma buah yang khas (Ayu Rini,2012), sedangkan manisan tamarillo selama penyimpanan 56 hari aroma khas sudah mulai berkurang hal tersebut karena faktor suhu dan udara disekitar penyimpanan manisan yang berpengaruh terhadap penurunan aroma manisan.

dahulu biji yang terdapat pada manisan karena cukup mengganggu.Saat penyimpanan agar memperhatikan suhu ruangan, Sebaiknya disimpan pada tempat yang tertutup agar manisan lebih tahan lama

\section{DAFTAR RUJUKAN}

https://id.wikipedia.org/wiki/Terung beland a/ diakses pada tanggal 13desember 2018

Desy Nofriati, Jurnal Agroindustri Balai Pengkajian Teknologi Pertanian Jambi, Vol. 3 No. 2, November 2013: 77 - 82 Dengan Judul Kajian Pengawetan Manisan Kering Buah Nenas (Ananas Comosus L. Merr) Selama Masa Penyimpanan. Diakses 20 April 2019

Fachhruddin, L. 1998. Memilih dan memanfaatkan bahan tambahan makanan. Trubus agriwidya. Ungaran. 
Jurnal Bosaparis: Pendidikan Kesejahteraan Keluarga

Volume 10, Nomor 3, November 2019

Fatah, M.A dan Y. Bachtiar,2004. Membuat aneka manisan buah.agro media pustaka,bogor.

Finarsih Tendean,dkk, jurnal teknologi pangan vol 7,no 7 tahun 2016, Karakteristik Fisikokimia Dan Sensori Manisan Tomat (Lycopersicum Esculentum). Diakses 23 April 2019

Nurul Asiah, Laras Cempaka,Wahyudi David, Februari 2018. Pendugaan Umur Simpan Produk Pangan, Jakarta: Penerbitan Universitas Bakrie

Potter, N.N. and J.H. Hotchkist. 1995. Food Science (5 th ed). Chapman and Hall. New York.

Rini, Ayu. 2012, Membuat Manisan Buah. Jakarta : Pustaka Mina 